\title{
Hydrodynamic Solvation of Poly(amido amine) Dendrimer Monolayers
}

\section{on Silica}

Aneta Michna*, Agata Pomorska, Małgorzata Nattich-Rak, Monika Wasilewska, Zbigniew Adamczyk

Jerzy Haber Institute of Catalysis and Surface Chemistry, Polish Academy of Sciences, Niezapominajek 8, PL-30239 Krakow, Poland

E-mail addresses: ncmichna@cyf-kr.edu.pl (A.Michna)

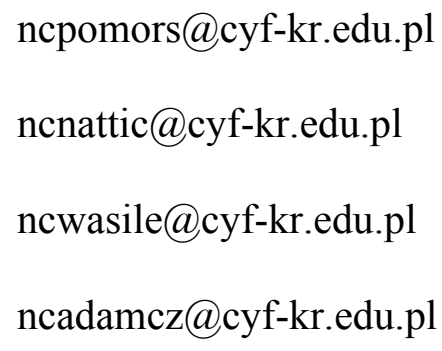

*Corresponding author

Aneta Michna

Jerzy Haber Institute of Catalysis and Surface Chemistry, Polish Academy of Sciences

Niezapominajek 8

PL-30239 Krakow, Poland

phone: +48126395202

fax: +48124251923

e-mail:ncmichna@cyf-kr.edu.pl

\section{Contents:}

1. Kinetics of adsorption/ desorption of poly(amido amine) dendrimers determined at various $\mathrm{pH}$ 


\section{Kinetics of adsorption/ desorption of poly(amido amine) dendrimers determined at}

various $\mathbf{p H}$

In Fig. S1 the dependences of kinetics of adsorption/ desorption of poly(amido amine) dendrimers deposited on silica coated QCM-D sensors were presented. The measurements were carried out for the ionic strength of $0.01 \mathrm{M}$ at pH 4.0 (a), and $\mathrm{pH} 7.4$ (b).

a)

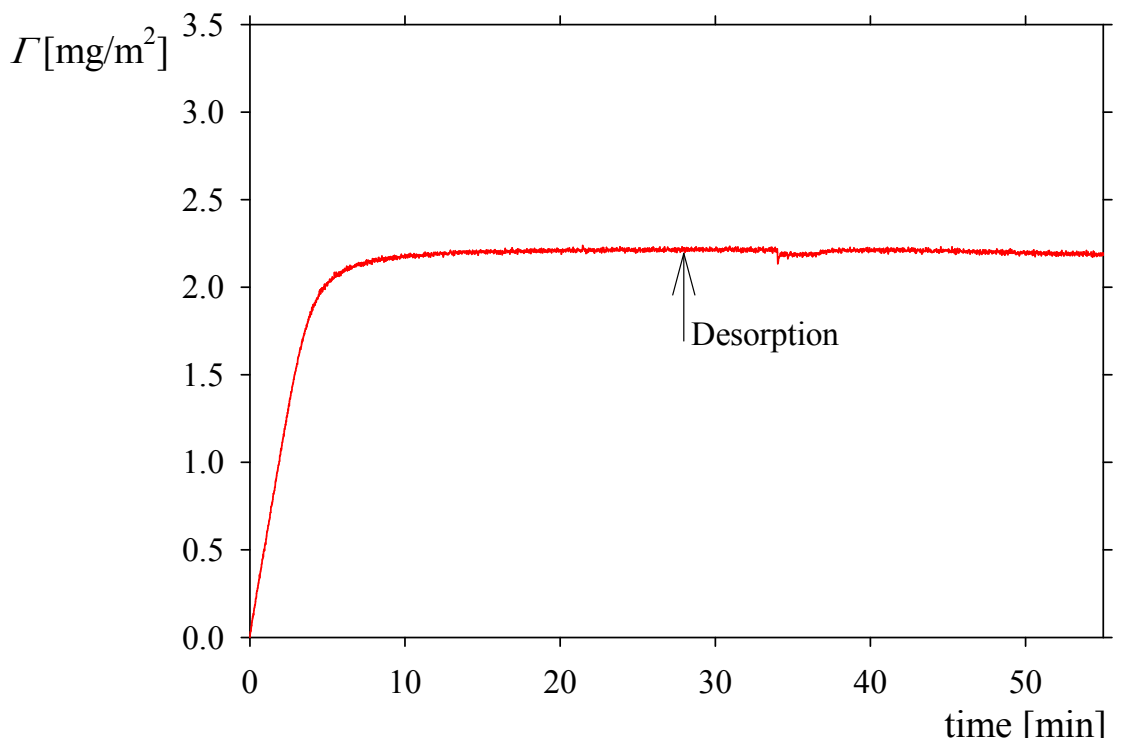

b)

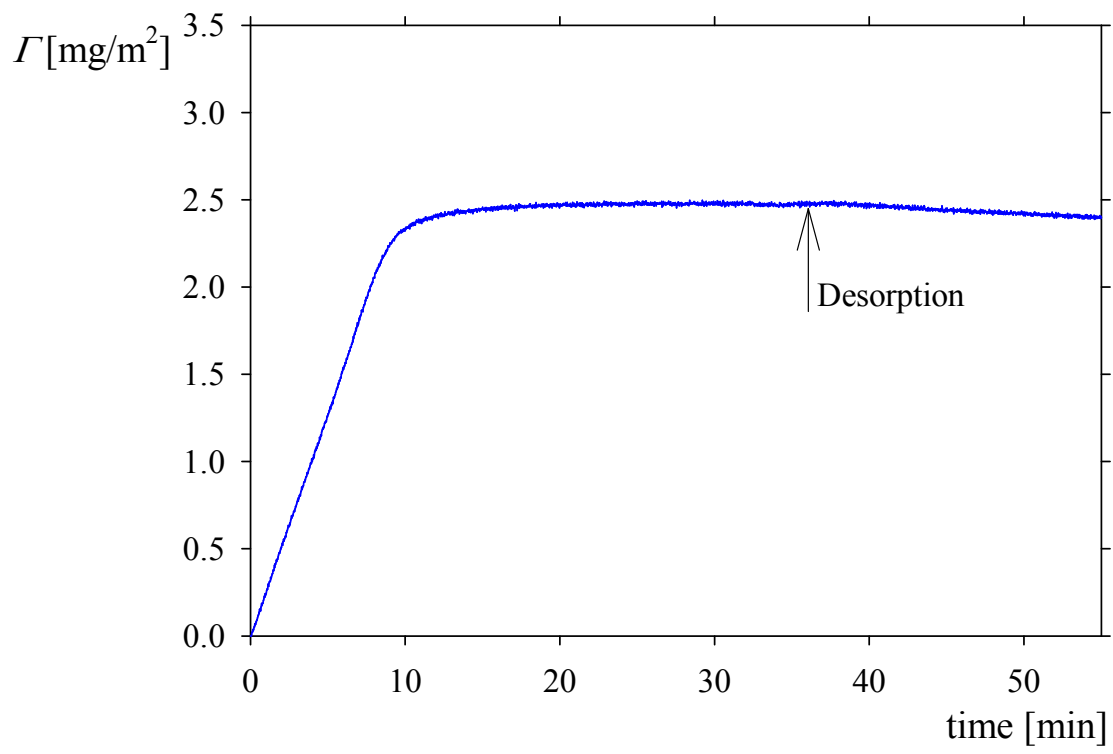

Fig. S1. The kinetics of poly(amido amine) dendrimers adsorption/ desorption at a) $\mathrm{pH} 4.0$ and b) $\mathrm{pH} 7.4$ evaluated by QCM-D. Bulk concentration of the dendrimers was equal to $1 \mathrm{mg}$ $\mathrm{L}^{-1}$, flow rate $2.5 \times 10^{-3} \mathrm{~cm}^{3} \mathrm{~s}^{-1}$, ionic strength $0.01 \mathrm{M} \mathrm{NaCl}$. 
Inspecting the results presented in Fig. S1, one can observe the linear increase in dendrimer coverage $(I)$ below 10 min for both $\mathrm{pH}$. The maximum coverages, which are equal to $2.2 \mathrm{mg} / \mathrm{m}^{2}$ for $\mathrm{pH} 4.0$ and $2.4 \mathrm{mg} / \mathrm{m}^{2}$ for $\mathrm{pH} 7.4$, respectively, are attained after approx. $600 \mathrm{~s}(10 \mathrm{~min})$ of adsorption. When the stationary values of the coverages were attained, no desorption was determined for both cases. The obtained dendrimer layers were stable even despite intensive washing with pure electrolyte. 